\title{
Research Paper: Epidemiology of Completed Suicides Referred to Forensic Pathology Organization of Tehran, crossuark Iran, During March 2011 to March 2016
}

\author{
Siamak Soltani ${ }^{1}$, Kamran Aghakhani ${ }^{1}$, Abdolrazzagh Barzegar ${ }^{2}$, Mohammadreza Ghadirzadeharani², Fardin Fallah ${ }^{1,2 *}$
}

1. Department of Forensic Medicine, School of Medicine, Iran University of Medical Sciences, Tehran, Iran.

2. Legal Medicine Research Center, Legal Medicine Organization, Tehran, Iran.

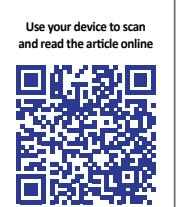

citation: Soltani S, Aghakhani K, Barzegar A, Ghadirzadeharani Gh, Fallah F. Epidemiology of Completed Suicides Referred to Forensic Pathology Organization of Tehran, Iran, During March 2011 to March 2016. International Journal of Medical Toxicology \& Forensic Medicine. 2017; 7(3):151-158. https://doi.org/10.18869/nirp.ijmtfm.7.3.151

doi : https://doi.org/10.18869/nirp.ijmtfm.7.3.151

Article info:

Received: 06 Jan. 2017

Accepted: 18 Apr. 2017

\section{ABSTRACT}

Background: Completed or successful suicide is the worst outcome of suicide attempts. This study is an epidemiologic investigation of successful suicides in Tehran, Iran.

Methods: In this routine-data-based study, the records of successful suicides in Forensic Pathology Organization of Tehran were investigated with respect to confidentiality of information during March 2011 to March 2016. The obtained data were analyzed by SPSS 11.5. Statistically significant level was considered at less than 0.05 .

Results: A total of 1773 cases with mean (SD) age of 33.19(13.11) years and male-to-female ratio of 3.1 were included in the study. The mean age of male victims was greater than that of female ones $(\mathrm{P}=0.01)$. Of victims, $821(46.3 \%)$ were single and $807(45.5 \%)$ were unemployed/ housewife. Methods of suicide were hanging in $962(54.6 \%)$, poisoning in $640(35.8 \%)$, falling in $88(5 \%)$, burning in $35(2 \%)$, shooting in $29(1.6 \%)$ and others in $19(1 \%)$ cases. Of poisoned cases, 283(44\%) were victims of aluminum phosphide ingestion. Generally, frequency of married victims was greater than single ones but by comparing genders, relative frequency of single victims was greater among males $(\mathrm{P}<0.001)$. There was statistically significant association between suicide methods and age $(\mathrm{P}=0.001)$, gender $(\mathrm{P}<0.001)$, and occupation $(\mathrm{P}<0.001)$ of victims. Among different methods, shooting and poisoning were used by the youngest cases. Relative frequency of females was greatest in victims of burning and poisoning. Regarding occupational categories, poisoning was most frequent in students.

Conclusion: In this study, the majority of successful suicides happened in people with occupational uncertainty, thus preventive measures should prioritize this issue. It seems that women with marital problems are also prone to suicide and social support programs should target this group, too. Association between the method of suicide and demography of victims will help us to recognize common methods in various groups of the society and establish appropriate preventive measures. While limiting access to supplies of suicide (like legislation on distribution of drugs for prevention of poisoning) is valuable, fundamental interventions at community level will be more effective in prevention of all kinds of suicide.

\section{* Corresponding Author:}




\section{Introduction}

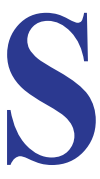

uicide behavior is a continuum and composed of suicide thoughts and plans, suicide attempts, and finally, completed suicide [1, 2]. Attempted suicide is the intentional act of a person in order to kill himself/herself (like poisoning, burning, or hanging) and completed or successful suicide is the worst outcome when the attempted person dies $[1,3]$. Based on the latest report of WHO in 2014, every year 800000 cases die of suicide and this rate is expected to double by 2020 , which is indicative of the severity and importance of this ubiquitous phenomenon as a global priority [1]. More than being a personal issue, suicide is a social problem with adverse consequences in communities [1,4]. Distribution of suicides is discrepant across the world and most attempts happen in developing countries with limited resources allocated to prevention of suicides and support of susceptible persons [1]. Approximately $60 \%$ of global suicides happen in Asian countries where there is high probability of underreporting due to various social, cultural, and religious barriers as well as inconsistent national registries $[5,6]$.

Compared to Middle Eastern countries, rate of suicide in Iran is high [7] and increasing in recent two decades [8]. Demographic, medical, social, and environmental factors are risk factors of suicide [1,9]. Suicide prevalence, methods, and mortality vary between and within countries; therefore, regional up-to-date surveys on suicide and related factors provide reliable evidence needed for addressing vulnerable populations and determining points of intervention for control and preventive programs $[1,10]$. In this study, we aimed to investigate patterns of completed suicides with regard to demography of victims from available records in Forensic Pathology Organization of Tehran, during a 5-year period.

\section{Materials and Methods}

All corpses with unnatural or suspected causes of death in Tehran are referred to Central Forensic Pathology
Organization for exploration and ascertainment of their cause of death. All referred bodies have a separate file with final diagnosis of the cause of death made by experts of Forensic Medicine.

There is also additional demographic information of victims in the files. In this routine-data-based study, we investigated all available records of completed suicides in the Forensic Pathology Organization of Tehran, Iran, during March 2011 to March 2016. Available information (method of suicide, season of suicide, age at the time of death, sex, marital status, occupation, and history of drug/ substance abuse of victims) was extracted from files. Suspected cases without definite diagnosis of suicide were not included in the study. Data were extracted by codes (without any name or identity of victims) and analyzed by SPSS version 11.5. Chi-squared, Mann-Whitney, and Kruskal-Wallis tests were used for data analysis. Statistically significant level was considered at less than 0.05 .

\section{Results}

Totally, 1773 cases of completed suicide entered the study. The mean (SD) age of victims was 33.19(13.11) years and ranged from 14 to 86 years. Of victims, $1338(75.5 \%)$ were male; thus male-to-female ratio was 3.1. In the study population, $821(46.3 \%)$ cases were single, 641(36.2\%) were married, 227(12.8\%) were separated, and $84(4.7 \%)$ were widow. According to recorded occupational categories, 807(45.5\%) cases were unemployed/housewife, 725(41\%) were self-employed, 147(8.3\%) were student, 72(4\%) were employee/retired, and $22(1.2 \%)$ were conscript soldiers. Regarding the terminology, self-employed victims in this study were laborers or service workers usually in seasonal and temporary jobs with low and unstable incomes. Employees were those worked in governmental or private organizations with monthly earning and insurance facilities even after retirement. Conscript soldiers were all young men at mandatory military service. Methods of suicide were hanging in $962(54.6 \%)$, poisoning in $640(35.8 \%)$, fall-

Table 1. Gender differences in marital status of study population

\begin{tabular}{cccc}
\hline Marital Status & Male/n (\%) & Female/n (\%) & P8(22.6) \\
\hline Single & $543(40.6)$ & $242(55.6)$ & $<0.001$ \\
Married & $579(43.3)$ & $70(16.1)$ & $<0.001$ \\
Separated & $157(11.7)$ & $25(5.7)$ & $<0.001$ \\
Widow & $59(4.4)$ & $<0.001$ & International Journal of \\
Medical Toxicology E Forensic Medicine
\end{tabular}


Table 2. Age distribution of study population according to prominent methods of successful suicide

\begin{tabular}{|c|c|c|c|c|}
\hline Suicide Method & Mean(SD), y & Min & Max & $\mathbf{P}$ \\
\hline Hanging & $34.52(13.54)$ & 14 & 86 & 0.001 \\
\hline Poisoning & $30.73(12.17)$ & 14 & 77 & 0.001 \\
\hline Fall & $35.53(13.40)$ & 17 & 80 & 0.001 \\
\hline Burning & $34.80(11.66)$ & 21 & 63 & 0.001 \\
\hline Shooting & $24.89(10.89)$ & 18 & 73 & 0.001 \\
\hline
\end{tabular}

Table 3. Gender differences in prominent methods of successful suicide in study population

\begin{tabular}{ccccc}
\hline Suicide Methods & Male/n (\%) & Female/n (\%) & P & M/F* \\
\hline Hanging & $766(57.2)$ & $196(45.1)$ & $<0.001$ & 3.9 \\
Poisoning & $447(33.5)$ & $193(44.3)$ & $<0.001$ & 2.3 \\
Fall & $64(4.8)$ & $24(5.5)$ & $<0.001$ & 2.7 \\
Burning & $17(1.3)$ & $18(4.1)$ & $<0.001$ & 0.9 \\
Shooting & $29(2.2)$ & $0(0)$ & $<0.001$ & -- \\
\hline *Male-to-female ratio & & & International Journal of \\
Medical Toxicology E For fonsic Medicin
\end{tabular}

ing in $88(5 \%)$, burning in $35(2 \%)$, shooting in $29(1.6 \%)$ and others in $19(1 \%)$ of cases. Among victims of poisoning, 283(44\%) were died due to ingestion of aluminum phosphide and $5(0.8 \%)$ were used organophosphates. All shooting victims were male and $18(62 \%)$ of them were conscript soldiers. Positive history of substance/drug abuse was recorded in 482(27.2\%) cases. Substances of abuse were hallucinogenic/psychoactive drugs in 352(73\%), opioids in 239(50\%), and alcohol in $135(28 \%)$ of abusers. Of substance abusers, $465(96 \%)$ were male and $208(43 \%)$ used mentioned substances in combination. In this study, season of suicide was summer in 594(33.5\%), spring in 581(32.8\%), autumn in $453(25.5 \%)$, and winter in $145(8.2 \%)$ cases.

Mean (SD) ages of male and female victims were $33.52(13.05)$ and 32.18(13.26) years, respectively $(\mathrm{P}=0.01)$; Thus female victims were significantly younger than male ones. There was statistically significant association between gender and marital status of victims $(\mathrm{P}<0.001)$ and relative frequencies of married, separated, and widow victims were greater among females (Table 1). There was statistically significant association between suicide method and age $(\mathrm{P}=0.001)$, gender $(\mathrm{P}<0.001)$, and occupation of victims $(\mathrm{P}<0.001)$; these associations are presented in Tables 2 and 3 and Figure 1.

\section{Discussion}

Various parts of health care systems take part in registration of suicide behavior, but in the cases of completed suicide, data from Forensic Pathology Organization are more objective than other sources. Due to forensic exploration of subjects and definitive diagnosis made by forensic experts, misclassification of recorded causes of death in referrals to this organization is less likely. In this study, the most common season of suicide was summer. Several studies in Iran have shown that suicide attempts are more prevalent in summer [11-13]. There is no consensus on

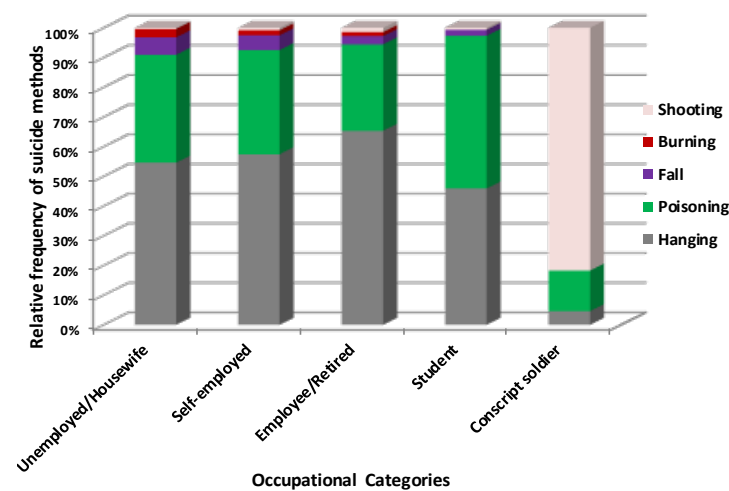

International Journal of
Medical Toxicology \& Forensic Medicine

Figure 1. Relative frequency of common suicide methods according to occupational categories of study population 
seasonal pattern of suicides in the world [14] and reasons for such pattern observed in some studies are unknown, but environmental and geophysical factors have been hypothesized to be important [15]. While in this study only referrals have been investigated, making a conclusion on seasonal pattern of suicide is not free of bias.

History of substance or alcohol abuse was only positive in about one-third of subjects. A meta-analysis of studies on suicide during recent three decades in Iran has also found similar rate for substance abuse [11] but this rate is greater in studies of other countries [16]. Such a difference in the prevalence of substance abuse can be explained by underreporting and shortcomings in our registration systems. As substance abuse is a risk factor for success of suicide attempts [4], surveillances on drug and substance abuse are cornerstones of suicide prevention programs. The only available indicator to determine socioeconomic status of victims in this study was their occupation. Most cases (86.5\%) were unemployed, homemakers, or those in low-income jobs and these people usually have similar financial difficulties, which may contribute to psychological problems and violence, and thus increase the risk of suicide [1]. Unemployment and low-income occupational positions have been recognized as risk factors of suicide in studies from Iran and other countries, even in developed countries [17-20]. These occupational categories should be targeted in suicide prevention programs.

The mean age of subjects in this study was 33.19 years. In the study of Shojaei et al. that also investigated completed suicides in Forensic Pathology Organization of Tehran during 2006-2010, the mean age of victims was 31.9 years [21]. Similarly, the mean age of suicide victims was 35.4 years in a study from Turkey [16] and 32.9 years in another report from Tanzania [17]. Studies from Iran [22] and Pakistan [23] demonstrate that cases of attempted suicide are younger compared to victims of successful suicide. Generally, probability of success of suicide attempts rises by age; this finding can be due to more violent methods used by older attempters, their greater tendency for dying and their lower resistance to physical injuries caused by attempts [10, 22, 24].

Regarding the poor prognosis of suicide attempts among older aged people, aging phenomenon which is growing in Iran and low social support for elderly in Asian countries, suicide prevention programs should address middle- and older-aged people whose psychological, medical, and social problems are usually neglected and thus at high risk for suicide [4, 25-27]. Suicide behaviors vary between genders [28]. In Iran and most parts of the world, suicide attempts are more prevalent among women but suicide mortality is greater in men $[10,24]$. Higher fatality rate of suicide among males can be attributed to their use of more violent methods and greater decisiveness for dying due to more responsibilities and stresses [29].

Male-to-female ratio of 3.1 in this study is high and comparable to developed countries [1]. This ratio may be lower in other parts of Iran because Tehran Province has the lowest fatality rate of women's suicide compared to other regions of Iran (especially western areas with the highest suicide fatality of women), which is reflective of cultural differences within our country [9]. Lower male-to-female ratio is usually observed in developing countries and deprived areas with high fatality of suicides among females $[1,18]$. Similar to this study, several reports from Iran [21], Turkey [16], and India [29] have shown that the mean age of male victims of suicide is greater than females. Reason for this age difference is not completely understood but possible explanation can be cultural, social, marital and financial problems in young women [30].

In this study, relative frequency of married victims was $10 \%$ greater than single ones. Statistics of Iran during 2001-2007 have shown that successful suicides are more frequent in married people [22]. Unlike popular beliefs, studies have revealed that marriage is not a protective factor for suicide in developing countries $[18,22,31$, 32]. In this study there was also greater frequency of successful suicides among married, separated and widow females, compared to their male counterparts. Other studies in Iran and Asian countries have reported higher rates of successful suicides in married women, which may be related to marital problems $[18,19]$.

Approximately half of the female suicide attempters in Iran have experienced marital violence [33]. Married and socially isolated women should be screened for psychological disorders and suicide ideations or attempts and social support programs should target them [1]. Prominent methods of suicide vary between countries and even in different regions of a county $[1,11,29$, 34]. Accessibility of supplies of a method is an important factor for its selection; however, demographic, cultural, and social factors also affect the chosen methods $[29,34]$. Methods of successful suicide are more violent with higher case fatality rates, compared to methods in attempted suicides. For example, poisoning has been the most prevalent method of attempted suicides in several studies but hanging has been the most common method among completed cases in the same studies [7, 22]. Lim- 
iting access to suicide supplies (like halting illegal drug distribution) is a promising measure taken in suicide prevention and control $[1,34]$.

The most prominent methods leading to successful suicide in this study were hanging and poisoning and they together comprised more than $90 \%$ of cases. Data from national suicide registration system of Iran during 2009-2013 also show that the most common methods in successful suicides have been hanging, drug overdose, and burning [10]. Similarly, hanging was the most prevalent method of completed suicides in other studies from India [29], Japan [35], and Turkey [16]. In recent two decades, hanging and poisoning have been the leading methods of suicide in Asia [6] and East Mediterranean Region [34]. In Iran, hanging is the most lethal suicide method and poisoning is the least one [22]; therefore high frequency of victims of poisoning in this study may be attributed to high prevalence of aluminum phosphide ingestion among them.

Other studies in Iran have shown high case fatality rate of poisoning with aluminum phosphide [36, 37]. Two important points about our poisoned victims are of public health importance and need especial attention by authorities; first, the younger age of victims of poisoning in comparison to victims of other methods and second the greater frequency of poisoning victims among students, compared to other job categories. Rigorous legislation on distribution of drugs or chemicals of abuse like aluminum phosphide and monitoring their consumption, especially at schools and among youth will limit occurrence of poisoning.

In the current study, methods other than hanging and poisoning were of low frequency. Fall is a fatal method of suicide attempts and is more prevalent in urban areas with high buildings and its case fatality rate is high [6]. In this study, only $5 \%$ of cases were victims of fall; however, likelihood of underreporting and misclassification should be considered as many intentional falls are reported as accidental. Burning is another fatal method with high prevalence in some regions of developing Asian countries, especially among women [34, 38]. Also In this study, burning was more prevalent among women. Intentional burning is most common in west of Iran and is attributable to social, financial, and cultural restrictions for women in these areas [39]. Shooting is a fatal method of suicide in the countries where firearms are accessible [34]. In Iran, there are regulations for access to firearms and this method is not a common choice of suicide.

The majority of shooting victims in this study were young conscript soldiers with access to firearms. Suicide among young soldiers needs further investigation with regard to their capacity and mental health and disciplines of boot camps [1]. There are several limitations to this study. Records of suicide victims lacked important information about past medical or familial history, thus the relationship of these important factors with suicide could not be investigated. Investigating socioeconomic status of victims only with regard to their occupations is not accurate and may be with bias but in the absence of other indicators such as income, it was the only available information at hand. The likelihood of underreporting of drug or substance abuse should be considered. Overestimation of the prevalence of hanging is likely because it is usually considered as intentional while, intentional poisoning, fall, and even burning may be classified as accidental. Further studies with more comprehensive data will overcome these limitations.

\section{Conclusion}

Older people, unemployed ones, or those with occupational uncertainty and women with marital problems are vulnerable groups to completed suicide and should be prioritized in preventive measures. Limiting access to means of prominent methods of suicide will prevent their occurrence and this will be best implemented for poisoning. However, this strategy will not be so effective in preventing methods such as hanging, fall, and burning. In such cases, primary prevention will be promising: fundamental interventions at community level for reducing risk factors, screening programs among vulnerable groups and individual tailored support programs are of great value in this regard.

\section{Acknowledgements}

This article is derived from Mr. Fardin Fallah's thesis in the Department of Forensic Medicine, School of Medicine, Iran University of Medical Sciences and was approved by Ethics Committee of Iran University of Medical Sciences (Ethics Code: IR.IUMS. rec.1394.9311223008).

\section{Conflict of Interest}

The authors declared no conflicts of interest.

\section{References}

[1] World Health Organization. Preventing suicide: A global imperative. Geneva: World Health Organization; 2014.

[2] O'Connell H. Recent developments: Suicide in older people BMJ. 2004; 329(7471):895-9. doi: 10.1136/bmj.329.7471.895 
[3] Azizpour Y, Asadollahi K, Sayehmiri K, Kaikhavani S, Abangah $\mathrm{G}$. Epidemiological survey of intentional poisoning suicide during 1993-2013 in Ilam Province, Iran. BMC Public Health. 2016; 16:902. doi: 10.1186/s12889-016-3585-9.

[4] Mościcki EK. Epidemiology of completed and attempted suicide: Toward a framework for prevention. Clinical Neuroscience Research. 2001; 1(5):310-23. doi: 10.1016/s15662772(01)00032-9

[5] Malakouti SK, Davoudi F, Khalid S, Asl MA, Khan MM, Alirezaei $\mathrm{N}$, et al. The epidemiology of suicide behaviors among the countries of the Eastern Mediterranean region of WHO: A systematic review. Acta Medica Iranica. 2015; 53(5):257-65. PMID: 26024698

[6] Wu KCC, Chen YY, Yip PSF. Suicide methods in Asia: Implications in suicide prevention. International Journal of Environmental Research and Public Health. 2012; 9(12):1135-58. doi: 10.3390/ijerph9041135

[7] Ghoreishi SA, Mousavinasab N. [Systematic review of researches on suicide and suicide attempt in Iran (Persian)]. Iranian Journal of Psychiatry and Clinical Psychology. 2008, 14(2):115-21.

[8] Rostami C, Daliri S, Sayehmiri K, Delpisheh A, Sayehmiri F. [The incidence of suicide attempt in Iran (2001-2012): A meta-analysis (Persian)]. Journal of Kermanshah University of Medical Sciences. 2016; 19(7):374-82

[9] Shojaei A, Shamsiani H, Moradi S, Alaedini F, Khademi A. [The study of successful cases of suicide commitment referred to Iran legal medicine organization in 2010 (Persian)]. Iranian Journal of Forensic Medicine. 2012; 18(1):7-15.

[10] Hajebi A, Ahmadzad-Asl M, Davoudi F, Ghayyomi R. Trend of suicide in Iran during 2009 to 2012: Epidemiological evidences from national suicide registration. Iranian Journal of Psychiatry and Behavioral Sciences. 2016; 10(4): 4398. doi: 10.17795/ijpbs-4398

[11] Shirazi HG, Hosseini M, Zoladl M, Malekzadeh M, Momeninejad M, Noorian K, et al. Suicide in the Islamic Republic of Iran: An integrated analysis from 1981 to 2007. Eastern Mediterranean Health Journal. 2012; 18(6):607-13.

[12] Haghighi H, Golmirzaee J, Mohammadi K, Moradabadi AS, Dadipoor S, Hesam AA. Investigating the relationship between the demographic variables associated with suicide in different seasons, among suicidal people in the Shahid Mohammadi Hospital, Bandar Abass, Iran. Journal of Education and Health Promotion. 2015; 4:3. doi: 10.4103/22779531.151868

[13] Shojaei A, Moradi S, Alaeddini F, Khoda-Doost M, Ghadirzadeh MR, Khademi A. [The association between completed suicides and season of the year in an Iranian population (Persian)]. Iranian Journal of Public Health. 2013; 42(3):293-7.

[14] Casey P, Gemmell I, Hiroeh U, Fulwood C. Seasonal and socio-demographic predictors of suicide in Ireland: A 22 year study. Journal of Affective Disorders. 2012; 136(3):862-7. doi: 10.1016/j.jad.2011.09.020.

[15] Partonen T, Haukka J, Nevanlinna H, Lönnqvist J. Analysis of the seasonal pattern in suicide. Journal of Affective Disorders. 2004; 81(2):133-9. doi: 10.1016/S0165-0327(03)00137-X
[16] Taktak Ş, Uzun İ, Balcığlu İ. Gender differences in completed suicides in Istanbul, Turkey. Journal of Affective Disorders. 2013; 145(3):394-9. doi: 10.1016/j.jad.2012.05.055

[17] Mgaya E, Kazaura MR, Outwater A, Kinabo L. Suicide in the Dar-es-Salaam region, Tanzania, 2005. Journal of Forensic and Legal Medicine. 2008; 15(3):172-6. doi: 10.1016/j. jflm.2007.06.002

[18] Chen YY, Chien-Chang Wu K, Yousuf S, Yip PSF. Suicide in Asia: Opportunities and challenges. Epidemiologic Reviews. 2011; 34(1):129-44. doi: 10.1093/epirev/m×r025

[19] Sheikholeslami H, Kani K, Ziaee A. [Survey of precipitating factors of suicide attempts in persons who referred to emergency department (Persian)]. Journal of Guilan University of Medical Sciences. 2008; 17(65):77-87.

[20] Hawton K. Sex and suicide: Gender differences in suicidal behaviour. British Journal of Psychiatry. 2000; 177(6):484-5. doi: 10.1192/bjp.177.6.484

[21] Shojaei A, Moradi S, Alaeddini F, Khodadoost M, Abdizadeh A, Khademi A. Evaluating the temporal trend of completed suicides referred to the Iranian Forensic Medicine Organization during 2006-2010. Journal of Forensic and Legal Medicine. 2016; 39:104-8. doi: 10.1016/j.jflm.2015.09.022

[22] Saberi-Zafaghandi MB, Hajebi A, Eskandarieh S, Ahmadzad-Asl M. Epidemiology of suicide and attempted suicide derived from the health system database in the Islamic Republic of Iran: 2001-2007. Eastern Mediterranean Health Journal. 2012; 18(8):836-41. PMID: 23057372

[23] Tahir MN, Akbar AH, Naseer R, Khan QO, Khan F, Yaqub I. Suicide and attempted suicide trends in Mianwali, Pakistan: Social perspective. Eastern Mediterranean Health Journal. 2013; 19(3):111-4. PMID: 24995732

[24] Martins Junior DF, Felzemburgh RM, Dias AB, Caribé AC, Bezerra-Filho S, Miranda-Scippa Â. Suicide attempts in Brazil, 1998-2014: An ecological study. BMC Public Health. 2016; 16:990. doi: 10.1186/s12889-016-3619-3

[25] Shah A. Elderly suicide rates in the United Kingdom: Trends from 1979 to 2002. Medicine, Science and the Law. 2007; 47(1):56-60. doi: 10.1258/rsmmsl.47.1.56

[26] Cheng ATA, Lee C-S. Suicide in Asia and the Far East. In: Hawton K, Van Heeringen K, editors. The International Handbook of Suicide and Attempted Suicide. New York: John Wiley \& Sons; 2000. doi: 10.1002/9780470698976.ch2

[27] Cattell H. Suicide in the elderly. Advances in Psychiatric Treatment. 2000; 6(2):102-8. doi: 10.1192/apt.6.2.102

[28] Schrijvers DL, Bollen J, Sabbe BGC. The gender paradox in suicidal behavior and its impact on the suicidal process. Journal of Affective Disorders. 2012; 138(1-2):19-26. doi: 10.1016/j. jad.2011.03.050

[29] Kanchan T, Menon A, Menezes RG. Methods of choice in completed suicides: Gender differences and review of literature. Journal of Forensic Sciences. 2009; 54(4):938-42. doi: 10.1111/j.1556-4029.2009.01054.x

[30] Rezaeian M. Suicide prevention in developing countries: A prioritized requirement issue. Journal of Health System Research. 2013; 9(5):441-8. 
[31] Fleischmann A, Bertolote JM, De Leo D, Botega N, Phillips $\mathrm{M}$, Sisask M, et al. Characteristics of attempted suicides seen in emergency-care settings of general hospitals in eight lowand middle-income countries. Psychological Medicine. 2005; 35(10):1467-74. doi: 10.1017/s0033291705005416.

[32] Vijayakumar L, John S, Pirkis J, Whiteford H. Suicide in developing countries. Crisis. 2005; 26(3):112-9. doi: 10.1027/0227-5910.26.3.112

[33] Sahraian A, Bahreini S, Mani A. Spousal abuse in married women with suicidal attempt in Shiraz, Iran. European Psychiatry. 2016; 33:274-5. doi: 10.1016/j.eurpsy.2016.01.730.

[34] Morovatdar N, Moradi Lakeh M, Malakouti S K, Nojomi M. [Frequency of methods of suicide in Eastern Mediterranean Region (EMRO) of WHO: A systematic review (Persian)]. Iranian Journal of Psychiatry and Clinical Psychology. 2013; 18(4):253-60.

[35] Toyoda Y, Nakayama A, Fujiwara H, Sana K, Matsuo $\mathrm{Y}$, Tanaka $\mathrm{H}$, et al. Characteristics of suicides according to prehospital records in Kishiwada City, Osaka Prefecture. Japanese Journal Of Public Health. 2008; 55(4):247-53. PMID: 18536339

[36] Shadnia S, Sasanian G, Allami P, Hosseini A, Ranjbar A, Amini-Shirazi N, et al. A retrospective 7-years study of aluminum phosphide poisoning in Tehran: Opportunities for prevention. Human \& Experimental Toxicology. 2009; 28(4):209-13. doi: 10.1177/0960327108097194

[37] Soltaninejad K, Faryadi M, Sardari F. Acute pesticide poisoning related deaths in Tehran during the period 2003-2004 Journal of Forensic and Legal Medicine. 2007; 14(6):352-4. doi: 10.1016/j.jflm.2006.12.011

[38] Rezaeian M. Epidemiology of self-immolation. Burns. 2013; 39(1):184-6. doi: 10.1016/j.burns.2012.05.022

[39] Nazarzadeh M, Bidel Z, Ranjbaran M, Hemmati R, Pejhan A, Asadollahi K, et al. Fatal suicide and modelling its risk factors in a prevalent area of Iran. Archives of Iranian medicine. 2016; 19(8):571-6. doi: 0161908/AIM.009 
